\title{
Isolation and Identification of Diesel oil-degrading Bacteria in used engine oil contaminated soil
}

\author{
MUSA, SI \\ Biology Research Group, Department of Biological Sciences, Admiralty University of Nigeria, \\ Delta State, Nigeria \\ Email: Musasa39id@gmail.com
}

\begin{abstract}
This study was conducted to isolate and identify bacteria associated with spent diesel oil contaminated site by collecting three replicates contaminated soil from the works department of Admiralty University of Nigeria, while the pristine soil was obtained from the biological garden. $\mathrm{pH}$ and temperature of all the samples were checked and the bacteria isolates were identified by morphological and biochemical techniques using the taxonomy scheme of Bergey's Manual of determinative bacteriology. The $\mathrm{pH}$ and temperature was highest (6.06 to 6.26) and (27 to $\left.30^{\circ} \mathrm{C}\right)$ in the contaminated soil than the pristine soil $(5.83)$ and $\left(23^{\circ} \mathrm{C}\right)$. The mean microbial load count was highest $\left(10.0 \times 10^{5} \mathrm{cfu} / \mathrm{ml}\right)$ in the diesel oil contaminated soils than the pristine uncontaminated soils $\left(9.0 \times 0 \times 10^{5} \mathrm{cfu} / \mathrm{ml}\right)$. However, there was no significant difference between the microbial loads in the soil samples. Eight bacteria species were obtained from the contaminated soil while six were obtained from the pristine soil. Klebsiella spp., Enterobacterae riginosa, Pseudomonas sp. and Escherichia coli showed highest growth in the contaminated soil and therefore may be considered as effective in the degradation of spent diesel oil hydrocarbons. It is likely that these bacteria when employed independently may be used to degrade hydrocarbons. Further research is necessary to assay for the degradative ability of the microorganisms.
\end{abstract}

DOI: https://dx.doi.org/10.4314/jasem.v23i3.10

Copyright: Copyright $($ C 2019 Musa. This is an open access article distributed under the Creative Commons Attribution License (CCL), which permits unrestricted use, distribution, and reproduction in any medium, provided the original work is properly cited.

Dates: Received: 17 November 2018; Revised: 19 January 2019; Accepted 22 January 2019

Keywords: Isolation, Identification, Degradation, Diesel oil, Pristine

Petroleum hydrocarbons such as diesel oil are the most ubiquitous organic pollutants (Liu et al., 2014). It is very dangerous to biological systems when exposed to at high toxicity level. The method and time of exposure plays a sensitive role in affecting the health of human beings and wild life. In Nigeria, it is a common process to dispose spent diesel oil into gutters, water drains and soil (Okonokhua et al., 2007). Recently, self-employed artisan automechanics are now moving to agricultural lands to set up engine workshops as a result of space challenge in developing parts of Nigeria (Musa et al., 2017). Spent diesel oil are used lubricating oils obtained after servicing and subsequently draining from automobile and generator engines. Thiscontains high percentage of aromatic and aliphatic hydrocarbons and other heavy metals such as nitrogen and sulphurthan fresh oils. These metals are introduced into the oil as a result of wear and tear of the engine (Chaineau et al., 2011). Spent diesel oil causes great damage to soil and soil microflora due to poor aeration, immobilization of soil nutrients and lowering of soil $\mathrm{pH}$ (Stegmann et al., 2011). It also changes the physical, chemical and microbiological properties of the soil (Okonokhua et al., 2007). At low concentrations, some of these heavy metals are essential micronutrients for plants, but they can cause metabolic disorders and growth inhibition when the concentration is high. Therefore, there is urgent need for clean up using different strategies. (Odjeda and Sadiq, 2002).

The clean up or containment of oil pollution can be achieved by physical and chemical means. However, the drawbacks of these methods are that there is always residual oil and damage to the ecosystem. The current remediation techniques include addition of biological agents such as microorganism to degrade or contain these pollutants. This strategy is known as bioremediation (Adams et al., 2012).It is seen as a cost effective and environmentally friendly alternative to physical and thermal clean up. It degrades the pollutants completely or transforms them into harmless substances using biological activity. As a natural process it is less invasive to the environment and can be engineered for on-site (in-situ) such as Bioaugmentation, as well as off site (ex-situ) such as

Email: Musasa39id@gmail.com 
use of Bioreactors (Patel and Shah, 2011). Some factors such as oxygen availability, $\mathrm{pH}$ of the environmental and temperature of the affected areas have been reported to influence biodegradation of hydrocarbon (Leahy and Colwell, 1990). For soil environments, the optimum rate of biodegradation is found within temperature of $30-40^{\circ} \mathrm{C}$ (Abdulsalam et al., 2011).A pH value of 6.5-8 has also been noted by (Brajesh et al., 2013) as favorable for microbial degradation. A study by (Khan et al., 2011) on biodegradation of petroleum contaminated soil by using indigenous isolated bacteria shows the activation as well as the incorporation of oxygen is the enzymatic key reaction catalyzed by oxygenases and peroxidases (Das and Chandran, 2010; Jain et al., 2011).For effective bioremediation using bacteria, different strains of bacteria found in the contaminated and uncontaminated soils needs to be isolated and characterized. (Tortora et al., 2014). This work aim to identify and isolate bacteria species present in spent engine oil contaminated soil at the works department of Admiralty University of Nigeria. The result will provide information that would lead to selection of bacterial species for effective degradation of spent engine oil and further studies on the identified microorganisms is recommended.

\section{MATERIALS AND METHODS}

Materials such as Weighing balance, autoclave, oven, aluminum foil, polythene bag, spirit lamp, ethanol, distilled water, slides, needle and syringe, microscope, sieve, measuring cylinder, Safranin, culture media, and Gram iodine were used for this experiment.

Experimental procedure: Diesel contaminated soil samples of $1 \mathrm{~kg}$ was taken from three (3) different spots in works department of Admiralty University of Nigeria and labeled S1, S2, and S3, while Pristine soil sample (control) of same mass was collected from unpolluted soil at the Biological garden of the University. The soil samples were collected above ground to a depth of $15 \mathrm{~cm}$ beneath the surface using small shovel and were put into new sterile polyethylene bags with aseptic conditions. The samples were made in three replicates and the temperature of each was recorded in accordance with the United State Environmental Protection Agency (USEPA, 2001). All glasswares to be used were thoroughly washed and sterilized using an autoclave at $121^{\circ} \mathrm{C}$ for $15 \mathrm{~min}$ (Venosa and $\mathrm{Zhu}, 2013$ ). The $\mathrm{pH}$ of the soil samples were determined using a $\mathrm{pH}$ meter (Stegmann et al., 2011).

For the sample preparation, $9 \mathrm{ml}$ of distilled water was dispensed into 12 sterile test tubes for the serial dilution. $1 \mathrm{ml}$ of each soil sample was transferred into the first tube of distilled water as $10^{-1}$ to $10^{-6}$ and mixed thoroughly. For the media preparation and sterilization, Plate Count Agar, Mac Conkey Agar and Eosin Methylene Blue Agar were utilized. After sterilization, the media was allowed to cool at $45^{\circ} \mathrm{C}$ and poured into sterile petri dishes in an aseptic condition until no growth was found after incubation at $37^{\circ} \mathrm{C}$ for 24 hours. $1 \mathrm{ml}$ of serially diluted microbial mixture from each test tube was aseptically transferred into the sterile petri dishes respectively and was incubated at a temperature of $37^{\circ} \mathrm{C}$ for 24 hours, after which they were examined for bacterial growth. The number of colonies on each plate were counted and recorded.

Bacteria species were isolated from the collected soil samples by serial dilution and Agar plating method. The bacteria isolates were further sub cultured for purity by streaking each of them into another freshly prepared medium. The purity was confirmed with the gram staining procedure. The bacteria screened for diesel degrading abilities was identified based on Colonial morphology, Microscopic observations such as the shape, size and Gram reaction properties and Biochemical reactions such as catalase test to see if the microbe has a protective enzyme capable of breaking down Hydrogen peroxide into oxygen and water according to (Jacob, 2016).Oxidase Test was also employed to aid in the identification of Pseudomonas and Neisseria. Coagulase Test was conducted to identify and differentiate Staphylococcus aureus and Staphylococcus epidermidis. Furthermore, Citrate Utilization Test was employed for the identification of Enterobacteria. The data collected was analyzed using the Statistical Package for Social Sciences (SPSS) version 20.0 (IBM Corp, 2011). Mean values were also compared using Analysis of Variance (ANOVA). Mean values were presented as Mean \pm Standard deviation. Post hoc test was done using the StudentNewman-Keuls (SNK). P $<0.05$ was considered to be statistically significant.

\section{RESULTS AND DISCUSSIONS}

$p H$ and Temperature of the Soil Sample: From the result obtained, the $\mathrm{pH}$ values ranges between 6.06 to 6.26 and 5.83 for the soil samples contaminated with spent diesel oil and pristine soil respectively (table 1). This is indicative that all the soil samples are slightly acidic in nature. This is likely due to the microbial activities going on in the soil samples. According to (Brajesh et al., 2013), bacteria can survive at different ranges of $\mathrm{pH}$ values but the degradation of hydrocarbons tends to favor near neutral $\mathrm{pH}$ of 6.5-8.0. However, the degradability declines as the $\mathrm{pH}$ shifts farther from neutral (Khan et al., 2011). This shows that more degradation is taking place in the 
contaminated soil than the pristine. The temperature ranged from $23^{\circ} \mathrm{C}$ to $30^{\circ} \mathrm{C}$ (table 1 ) for all the samples with the pristine sample having the lowest temperature of $23^{\circ} \mathrm{C}$. This is likely due to the lower rate of biodegradation because elevation in temperatures decreases the viscosity of hydrocarbons, which results into greater rates of diffusion. This allows the petroleum pollutants to be more accessible for the microbes (Atlas, 2018).

\begin{tabular}{|c|c|c|}
\hline Samples & pH & $\begin{array}{l}\text { Temperature } \\
\left({ }^{\circ} \mathrm{C}\right)\end{array}$ \\
\hline Sample 1 & 6.26 & 28 \\
\hline Sample 2 & 6.11 & 30 \\
\hline Sample 3 & 6.08 & 27 \\
\hline Control & 5.83 & 23 \\
\hline
\end{tabular}

Microbial Load Count: On the Plate count agar and McConkey agar, microbial load counts were higher in the pristine uncontaminated soil than the diesel contaminated soils (figure 1). However, the microbial load count recorded on Eosin methylene blue agar $\left(13.0 \times 10^{5} \mathrm{cfu} / \mathrm{ml}\right)$ was significantly higher $(\mathrm{p}<0.05)$ in the diesel contaminated soil than in pristine uncontaminated soil. $\left(8.0 \times 10^{5} \mathrm{cfu} / \mathrm{ml}\right)$. The mean microbial load count was highest in the diesel contaminated soils than the pristine uncontaminated soils (table figure 2). These were however not significantly different $(\mathrm{p}>0.05)$.

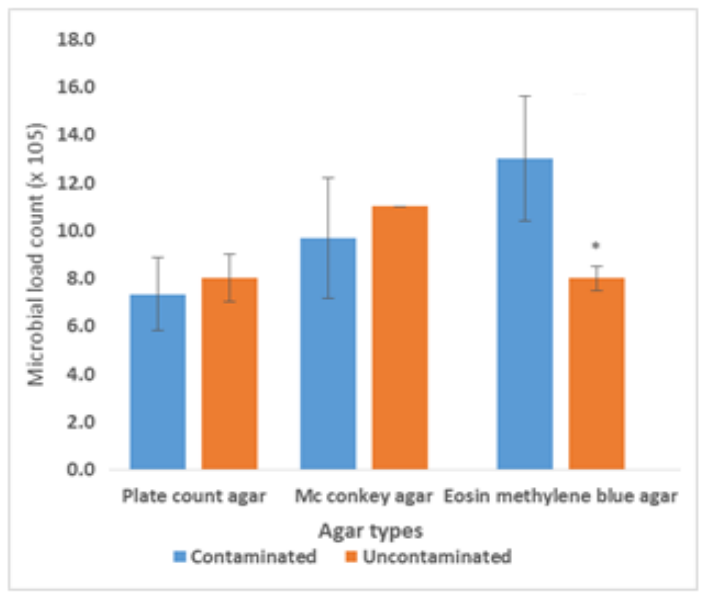

Fig 1: Microbial load count comparison between the contaminated and uncontaminated soil on each agar type used; *Mean significantly different at $\mathrm{p}<0.05$

Microbial Isolates: For the contaminated soil samples, a total of eight (8) bacteria species were isolated. These include Pseudomonas aeriginosa, Escherichia coli, Neisseria spp., Bacillus subtilis, Micrococcus spp., Streptococcus spp., Enterobacterae riginosa and Klebsiella spp. However for the pristine soil samples (6) six bacteria species were isolated which includes all but not Enterobacterae riginosa and Klebsiella spp. (table 2). Escherichia coli, Pseudomonas aeriginosa and Klebsiella spp. were observed to have the highest numbers of growth on the diesel contaminated soils (table 2). This result is in line with the work of Ugoh and Moneke (2011) who reported that the bacterial isolates from the soil contaminated with petroleum products from the different sites showed Pseudomonas sp., Bacillus sp. and Klebsiella spp. having highest percentage occurrence frequency of $60 \%$.On the other hand, only Pseudomonas aeriginosa had highest growth on the uncontaminated soil. Also, Micrococcus sppand Bacillus subtilis were lowest in occurrence on the contaminated soils (table 2), while Bacillus subtilis, Micrococcus spp. and Streptococcus spp. were the lowest occurring bacterial species on the uncontaminated soils. This is consistent with the work of Alexander (2014) who reported that Pseudomonas spp., Escherichia coliand Klebsiella spp. were found to utilize the diesel soil samples in the soil environment in Keffi, Nasarawa State.

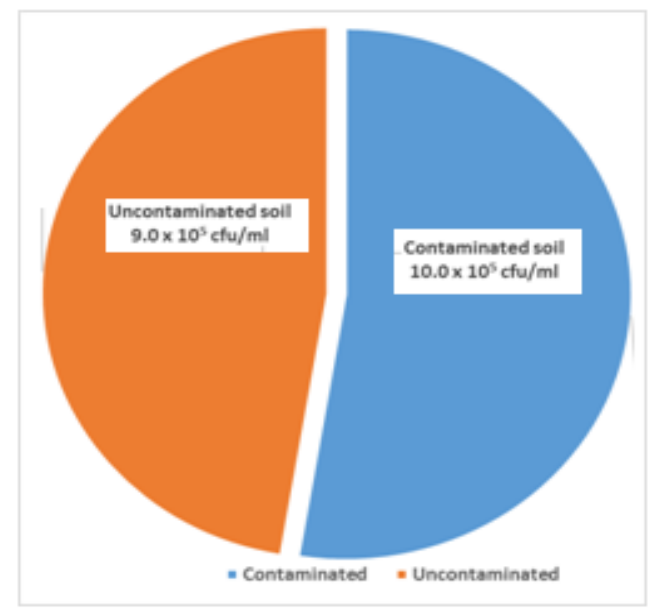

Fig 2: Mean total microbial load count (x $10^{5} \mathrm{cfu} / \mathrm{ml}$ ) between the contaminated and uncontaminated soils $(\mathrm{p}>0.05)$

Morphological Characterization: The results of the morphological characterization of identified bacteria strains for all the soil samples shows a circular shape for Sample 1a, 2a, 3c and sample 4c. While irregular for Sample 1b, 1c, 2b, 2c, 3a, 3b, 4a and Sample 4b. All the isolates in sample 1a, 2a, 3a, 3c and $4 \mathrm{c}$ had an entire edge, sample 1b, 1c, 2b, 2c, 3b, 4b and 4c had a lobate edge. All the isolated colonies were membranous. The isolated colonies in sample 1a, 2a, and $4 \mathrm{c}$ had a convex elevation, sample $1 \mathrm{~b}, 1 \mathrm{c}$, and $2 \mathrm{c}$ had a flat elevation, sample $3 \mathrm{a}, 3 \mathrm{~b}, 3 \mathrm{c}, 4 \mathrm{a}$, and $4 \mathrm{~b}$ had a raised elevation. All the isolated colonies in sample 1a, 1c, 2a, 2b, 2c, 3a, 4a, 4b and 4c have a smooth colony surface, sample $1 \mathrm{~b}, 3 \mathrm{~b}$ and $3 \mathrm{c}$ have a glistering colony surface. 
Table 2: Microorganisms found in Contaminated and Pristine soil sample

\begin{tabular}{lll}
\hline S/N & Microorganisms in diesel oil contaminated soil samples & Microorganisms in pristine soil samples \\
\hline $\mathbf{1}$ & Pseudomonas aeriginosa (a) & Pseudomonas aeriginosa (a) \\
$\mathbf{2}$ & Escherichia coli (a) & Escherichia coli \\
$\mathbf{3}$ & Bacillus spp (b) & Bacillus spp (b) \\
$\mathbf{4}$ & Neisseria spp & Neisseria spp \\
$\mathbf{5}$ & Micrococcus spp (b) & Micrococcus spp (b) \\
$\mathbf{6}$ & Streptococcus spp & Streptococcus spp (b) \\
$\mathbf{7}$ & Enterobacteraeriginosa & \\
$\mathbf{8}$ & Klebsiellaspp (a) & \\
\hline & (a) Shows microorganisms with highest growth while, (b) Shows microorganisms with lowest growth
\end{tabular}

Table 3: Biochemical characterization of bacteria isolate

\begin{tabular}{llllllllll}
\hline Colony & GR & CS & OX & CT & CI & CO & G & S & L= Likely Organism \\
\hline Sample 1a & GNB & Rod & - & + & + & + & A & AA & Pseudomonas species \\
Sample 1b & GPB & Cocco & + & + & + & + & A & AA & Neisseria species \\
Sample 1c & GNB & Cocci & + & + & + & + & A & AA & Streptococcus species \\
Sample 2a & GPB & Rod & - & + & + & - & - & A & Bacillus species \\
Sample 2b & GPB & Rod & - & + & + & + & A & AA & Klebsiella species \\
Sample 2c & GPB & Cocco & + & + & + & - & A & AA & Micrococcus species \\
Sample 3a & GNB & Rod & - & + & + & + & A & - & Enterobactera eriginosa \\
Sample 3b & GNB & Rod & + & + & + & + & A & AA & Pseudomonas species \\
Sample 3c & GNB & Rod & + & + & - & - & A & AA & Pseudomonas species \\
Sample 4a & GPB & Cocci & + & + & + & - & A & A & AKlebsiella species \\
Sample 4B & GNB & Rod & - & + & - & + & A & AA & Escherichia coli \\
Sample 4C & GNB & Rod & - & - & + & + & A & AA & Escherichia coli \\
\hline
\end{tabular}

Keys: GR-Gram reaction, $C S$ - Cell shape, OX-Oxidase, CT-Catalase, CI-Citrate, CO-coagulase, $G$ - Glucose, $S$ - Sucrose, $L$ - Lactose, AAcid production, + means positive, - means negative, GNB-Gram negative bacteria, GPB-Gram positive bacteria.

Biochemical Characterization of Bacteria Isolates: The result of the biochemical characterization (table 3) confirmed that Sample 1a pure culture was Pseudomonas species, sample 1b pure culture was Neisseria species and sample 1c pure culture was Streptococcus species. Sample 2a pure culture was Bacillus species, 2b pure culture was Klebsiella species and 2c pure culture was Micrococcus species. Sample 3a pure culture was Enterobacterae riginosa, $3 \mathrm{~b}$ pure culture was Pseudomonas species and 3c pure culture was Pseudomonas species. Sample 4a pure culture was Klebsiella species, $4 \mathrm{~b}$ pure culture was Escherichia coli and 4c pure culture was Escherichia. This result (table 3 ) is in accordance with Annweiller et al., (2000) reported that the isolate showing maximum oil degradation abilities was Gram negative, Escherichia coli, Pseudomonas sp., and catalase positive. Few studies Odjegba and Sadiq (2002); Jain et al., (2011); Makut and Ishaya (2010); Megharajet al., (2002); Sepahi et al.,(2008) have been reported on the roles of Escherichia coli, Pseudomona ssp., in hydrocarbon bioremediation.

Conclusion: This study aim to identify and isolate microorganisms found in pristine and diesel oil contaminated soil in Admiralty University of Nigeria. The result obtained in this study shows eight bacteria were isolated from the diesel contaminated soil while six were isolated for the pristine soil. Klebsiella spp. and Enterobacterae riginosa strains found in the contaminated soil are indigenous and effective in the utilization of crude oil as the sole carbon and energy source. Furthermore, the temperature and $\mathrm{pH}$ were optimum in the contaminated soil than the pristine soil which also indicates possible degradation by the bacteria. The study provides information that would lead to selection of bacterial species that could be employed for bioremediation in environments polluted with used engine oil.

\section{REFERENCE}

Abdulsalam, S; Bugaje, I.; Adefila, S; Ibrahim, S. (2011). Comparison of biostimulation and bioaugmentation for remediation of soil contaminated with spent motor oil. Int. J. Environ. Sci. Technol. 8: 187-194

Adams, G; awari, P; Igelenyah, E. (2012). Bioremediation, biostimulation and bioaugumentation. A review. Int. J. Environ. Bior. Biod. 3:28-39

Alexander, M. (2014). Biodegradation and Bioremediation. San Diego: Academic Press, pp. 43-48

Annweiller, E; Richnow, H; Antranikian, G; Hebenbrock, S; Garms, C; Franke, S; Francke, W; Michaelis, W. (2000).Appl. Environ. Microbiol.66:518-523

Atlas, R; Bartha, R. (2018). Biodegradation of petroleum in soil environment at low temperatures. J. Microbiol., 17: 1652-1857 
Brajesh, K; Singh, M; Allan, J; Allun, W; Denis, J. (2013). Effect of soil $\mathrm{pH}$ on the biodegradation of Chlorpyrifos and isolation ofaChlorpyrifosgefrading bacterium. J. Appl. Environ. Microbiol. 69(9): 5198-5204

Chaineau, H; Rougeux, G; Yepremian, C; Oudot, J. (2011). Effects of nutrient concentration on the biodegradation of crude oil and associated microbial populations in the soil. J. Soil. Bio. Biochem. 37(8): 1490-1497

Das, N; Chandran, P. (2010). Microbial degradation of petroleum hydrocarbon contaminants: An Overview'. Biotech. Res. Intl. 13: 1-9

IBM SPSS (2011). Statistics for Windows, version 20.0. Armonk, NY:IBM Corp Aromatic Compounds. 28(5):242-272

Jacob, J. (2016). The significance of polycyclic aromatic hydrocarbons as environmental carcinogens. 35 years research on PAH-a retrospective. J. PolycyclicIBM Corporation (2011)

Jain, K; Gupta, K; Gaur, K; Lowry, M; Jaroli, D.; Chauhan, K. (2011). Bioremediation of petroleum oil contaminated soil and water. Res. J. Environ. Toxicol. 5(1):1-26

Khan, J; Rizvi, S. (2011). Isolation and characterization of micro-organism from oil contaminated sites.Advan. Appl. Sci. Res. 2 (3):455-460

Leahy, J; Colwell, R. (1990). Microbial degradation of hydrocarbons in the environment. Microbiol. Rev. 54: 305-315

Liu, R; Xiao, N; Wei, S; Zhao, L. (2014). Rhizosphere effects of PHA-contaminated soil phytoremediation using a special plant named Fire phoenix. Sci. Total. Environ. 473-474: 350358

Makut, M; Ishaya, P. (2010). Bacterial species associated with soils contaminated with used petroleum products in keffi town, Nigeria. Afr. J. Microbiol. Res. Grp. 4(16): 1698-1702
Megharaj, S; Singleton, I; McClure, N; Naidu, R. (2002). Influence of petroleum hydrocarbon contamination on microalgae and microbial activities in the long term contaminated soil. Arch. Environ. Cont. Toxicol. 38: 439-445

Musa, S; Njoku, K; Ndiribe, C; Oke, F. (2017). The Effect of Vermi Tea on the Growth Parameters of Spinaciaoleracea L. (Spinach). J. Environ. Sci. Poll. Res. 3(4): 236-238

Odjegba, V; Sadiq, A. (2012). Effect of spent engine oil on growth parameters, Chlorophyll and protein levels of Amaranthushybridus L. The Environmentalist, 22: 23-28

Okonokhua, B; Ikhajiagbe, B; Anoliefo, G; Emede, T. (2007). The effects of spent engine oil on soil properties and growth of maize ( Zea mays L.) J. Appl.Sci. Environ. Manage. 11(3): 147 - 152

Patel, V; shah, K. (2011). Petroleum hydrocarbon pollution and its Biodegradation. Int. J. Chemtech. Appl. 2(3): 63-80.

Sepahi, A., Golpasha, D., Emami, M. and Nakhoda, M.(2008). Petrology of major granitic plutons of the northwestern part of SanandajSirjan metamorphic belt. Iran. J. Environ. Health. Sci. Eng. 5(3): 149-154

Stegmann, R; Lotter, S; Heerenklage, J. (2011). Biological treatment of oil- contaminated soils in bioreactors. J. Inter. Microbiol. 4(3): 231-235

Tortora, J; Funke, R; Case, L. (2014).Microbiology: An Introduction. England. P.I. 11th Edition

Ugoh, S; Moneke, L (2011). Isolation of bacteria from engine oil contaminated soils in auto mechanic workshops in Gwagwalada, Abuja. J. Acad. Arena. 2(5): 20-33

United State Environmental Protection Agency (2001). An analysis of composting as an environmental remediation technology. USEPA Solid Waste and Emergency Response. (5305W). EPA 530-R-98-008, pp. 2-38

Venosa, A; Zhu, X. (2013). Biodegradation of crude oil contaminating marine shorelines and freshwater wetlands. Spill Science and Technology Bulletin. 8(2):163-178 